\title{
Efecto de la aireación y la concentración de cloruro sódico en el desarrollo de la flora microbiológica y en los parámetros fisicoquímicos en la fermentación de Olea europaea L. c.v. Sevillana al estilo negras naturales en la zona de La Yarada-Tacna
}

\author{
Por C. Clavijo Koc ${ }^{a}$, W. Garragate Rospigliosi ${ }^{a}$, M. Gallegos Arata ${ }^{a}$, P. Lanchipa Sepúlveda ${ }^{a}$ \\ y C. Villalobos Ochoa ${ }^{a}$
a Laboratorio CITELAB del Módulo de Servicios Tacna CITE Agroindustrial. Panamericana Sur Km 1303 Ciudadela Zofratacna-Perú, Dirección postal actual nํㅜ 331
* Corresponding autor: claudiavck@ hotmail.com

\section{RESUMEN}

Efecto de la aireación y la concentración de cloruro sódico en el desarrollo de la flora microbiológica y en los parámetros fisicoquímicos en la fermentación de Olea europaea L. c.v. Sevillana al estilo negras naturales en la zona de La Yarada-Tacna

La fermentación aerobia de aceituna variedad Sevillana estilo negra se desarrolló en los parámetros de acidez fija entre de 1.2 a $1.5 \%$, debido a la concentración de cloruros en la salmuera los cuales se mantuvieron por debajo de $6.5 \%$ durante el periodo de fermentación en los 9 tratamientos ensayados lo que permitió el desarrollo de bacterias lácticas. No hubo diferencia en la evolución del pH entre la fermentación con aireación o en condiciones anaeróbicas alcanzándose valores menores a 3.5. La aireación tiene un efecto significativo en la purga del $\mathrm{CO}_{2}$ en la salmuera e incrementó la población de levaduras aerobias; así mismo en los tratamientos con $12 \%$ de sal se favoreció el desarrollo de levaduras fermentativas al inicio de la fermentación. La concentración de azúcares reductores en el fruto disminuyó significativamente en los tratamientos con aireación, acelerando el proceso de fermentación con respecto a la fermentación anaerobia. ción.

PALABRAS CLAVE: Aceituna - Aireación - Fermenta-

\section{SUMMARY}

Aeration and Sodium chloride in the develop of microflora and phycochemical parameters on the Olea europaea L. cv Sevillana fermentation at the natural black style in La Yarada zone-Tacna

The aerobic fermentation of the table olive variety, Sevillana a black style, was carried out, taking into account the parameters of fermentation of fixed acidity between 1.2 to $1.5 \%$ and depended on the chloride concentration in the brine. This concentration was under $6.5 \%$ in the 9 treatments assayed, allowing for the lactic bacteria to develop. In the aerobic fermentation there were no differences in the decline of $\mathrm{pH}$ in relation to the anaerobic fermentation, which reached values below 3.5. The air effect is of great significance in the purge of the carbon dioxide in the brine. At the same time, the effect of air significantly affects the increase in aerobic yeast. The facultative anaerobic yeasts developed in the treatments with an initial salt level of $12 \%$ at the beginning of fermentation. The reduction of sugar concentration into the fruit decreased significantly in the treatment with air. Aerobic fermentation is more rapid than anaerobic fermentation.

KEY-WORDS: Aeration - Fermentation - Olive table.

\section{INTRODUCCIÓN}

En el sur del Perú, se procesa aceituna negra natural, siendo una de las principales zonas La Yarada, ubicada en la región de Tacna. La principal variedad de aceituna que se procesa es la Sevillana (Olea europaea L.), esta planta llegó al Perú en la época de la colonización desde España, adaptándose al clima de la zona, la aceituna se cosechan por el método del ordeño con un índice de madurez de 4.5 a 5 entre los meses de Mayo a Agosto y la fermentación se realiza colocándolas en salmuera con concentraciones de sal de $8^{\circ}$ a $12^{\circ}$ Bé lo cual varía según la metodología de cada productor, por 4 meses en condiciones anaerobias.

La aplicación de aire en el proceso fermentativo, disminuye la concentración del $\mathrm{CO}_{2}$ producido por la respiración del fruto y por los procesos fermentativos (Sánchez et al., 2006), la flora que se desarrolla es principalmente aerobia. Al final del proceso los frutos siguen tersos y firmes (Fernández et al., 1992).

Si bien se conoce el desarrollo microbiológico de aceitunas negras naturales españolas y de otras latitudes, se desconoce el desarrollo microbiológico de las aceitunas negras naturales de la variedad Sevillana. La acidez que se produce en la fermentación sugiere un predominante desarrollo de bacterias lácticas. El factor que mayor medida condiciona el desarrollo de bacterias lácticas es la concentración de sal y en menor medida la presencia de oleuropeína y otros polifenoles que inhiben el desarrollo de estos microorganismos, (Duran et al., 1997). 
La concentración de azúcares fermentables en la pulpa difiere entre variedades y disminuyen a medida que avanza la fermentación (Garrido et al., 1997). Según lo observado por Fernández et al. (1985), el contenido de azúcares reductores es entre $2 \%$ y $3 \%$, en aceituna verde, disminuyendo según avance su estado de madurez. El desarrollo de lactobacilos, se ve favorecido por las vitaminas producidas por levaduras del género Picchia membranaefasciens, Lodderomyces elongisporus y Saccharomyces cerevisiae (Durán et al., 1997). La presencia de levaduras durante el proceso fermentativo ocasionando la producción de $\mathrm{CO}_{2}$ que lleva a la aparición del alambrado y vejigas (gas- pocket) en los frutos (García et al., 1985); además algunas levaduras y la presencia de mohos se asocian al ablandamiento del fruto (Garrido et al., 1979). En aceitunas marroquíes, la fermentación predominante es por Lactobacillus pentosus Lactobacillus plantarum y Lactobacillus pentosaceus. (Ghabbour et al., 2011), a diferencia, en aceitunas negras naturales de Grecia y España los microorganismos que predominan son las levaduras. (Balatsouras, 1967; Garrido et al., 1997).

El objetivo del presente trabajo es conocer el efecto que tiene la aplicación de la aireación en la evolución del proceso fermentativo y en las características finales de aceitunas negras naturales de la variedad Sevillana en el sur del Perú.

\section{MATERIALES Y MÉTODOS}

\subsection{Materia Prima}

Los frutos procesados son de la variedad Sevillana (Olea europaea L), recolectados con un índice de madurez de 4.5. (COI, 1985), a inicios del mes de Junio, 2012.

\subsection{Fermentación}

La fermentación se llevó a cabo en la zona de la Yarada a Latitud: $18^{\circ} 12^{\prime} 41.3^{\prime \prime}$ y Longitud: $70^{\circ} 31^{\prime}$ 25.9"; la temperatura osciló entre $9-24^{\circ} \mathrm{C}$, datos recopilados de Senamhi-estación La Yarada.

Los tanques de fermentación son de fibra de vidrio con una capacidad de 1000 litros y un contenido neto de $700 \mathrm{~kg}$ de aceituna, los cuales disponen de un sistema de aireación similar al descrito por García et al. (1985).

\subsection{Análisis Fisicoquímicos}

El pH se determinó potenciométricamente en un equipo marca Jenwey modelo 3510; la acidez total y acidez fija se midió mediante la técnicas descritas por Amelio \& De Mauro (2000), la cuantificación de azúcares reductores se realizó por espectrofotometría utilizando la metodología de Smogyi y Nelson (Nelson, 1944) y la concentraciones de cloruro de sodio y $\mathrm{CO}_{2}$ disuelto en salmuera se midieron según la metodología de Fernández (1985).

\subsection{Análisis Microbiológico}

Para la cuantificación de Enterobacteriaceas se utilizó la técnica de la Norma AOAC, (2007); el recuento de bacterias ácido lácticas se realizó utilizando medio de cultivo Agar MRS marca Merck, posteriormente se realizaron pruebas complementarias al $5 \%$ de las colonias aisladas: prueba de la catalasa, prueba de la oxidasa y coloración gram para confirmar el desarrollo de Lactobacillus sp u otras bacterias lácticas, se utilizó la técnica de recuento en placa por diseminación (ICMSF, 1983). En el aislamiento de levaduras se utilizó el medio OGYE adicionado con oxitetraciclina al $0.2 \%$ y se analizó la salmuera mediante la técnica de recuento en placa por diseminación (ICMSF, 1983). Para realizar el recuento de levaduras anaerobias facultativas de metabolismo fermentativo, se utilizaron jarras Gaspar con atmósfera modificada con $\mathrm{CO}_{2}$.

La identificación de bacterias lácticas se realizó mediante el sistema API $50 \mathrm{CH}$ y en la identificación de levaduras se utilizó el sistema API 20C AUX (API SISTEMS, Francia).

\subsection{Diseño de las experiencias}

Se realizó una experimentación Factorial $2^{3}$ (Software Stat Graphic Centurión)

Factores: Aireación (L/h/Lc, litros de aire/hora/ litro de capacidad), niveles: 0.0-0.1 y 0.2 (es decir 0,100 y $200 \mathrm{~L}$ de aire $\times$ hora $^{-1}$ ), Cloruro de Sodio $(\%$, inicial $\mathrm{p} / \mathrm{v})$ niveles: $6-9-12$. Se procesaron un total de 18 tanques con $700 \mathrm{~kg}$ de aceituna, obteniendo un total de 9 tratamientos (Tabla 1).

Variables Dependientes: Recuento de levaduras aerobias (log ufc $\mathrm{mL}^{-1}$ ), recuento de levaduras fermentativas (log ufc $\mathrm{mL}^{-1}$ ), recuento de bacterias lácticas (log ufc $\mathrm{mL}^{-1}$ ), concentración de acidez fija ( $\mathrm{g}$ ac. láctico $100 \mathrm{~mL}^{-1}$ ), concentración de $\mathrm{CO}_{2}$ disuelto

Tabla 1

Tratamientos realizados en la experimentación factorial $2^{3}$ y concentración de azúcares reductores en la salmuera a los $\mathbf{3 0}$ días de fermentación

\begin{tabular}{crcc}
\hline $\begin{array}{c}\text { Código de los } \\
\text { tratamientos }\end{array}$ & $\begin{array}{c}\mathbf{N a C l} \\
\%\end{array}$ & $\begin{array}{c}\text { Aireación } \\
\mathbf{L ~ h}^{-1}\end{array}$ & $\begin{array}{c}\text { Azúcares } \\
\text { Reductores }\end{array}$ \\
\hline T1 & 6 & 0.0 & $1.16 \mathrm{c}^{*}$ \\
T2 & 9 & 0.0 & $0.90 \mathrm{~b}$ \\
T3 & 12 & 0.0 & $1.52 \mathrm{~d}$ \\
T4 & 6 & 0.1 & $0.53 \mathrm{ab}$ \\
T5 & 9 & 0.1 & $0.62 \mathrm{ab}$ \\
T6 & 12 & 0.1 & $0.54 \mathrm{ab}$ \\
T7 & 6 & 0.2 & $0.36 \mathrm{ab}$ \\
T8 & 9 & 0.2 & $0.36 \mathrm{ab}$ \\
T9 & 12 & 0.2 & $0.52 \mathrm{ab}$ \\
\hline
\end{tabular}

Nota: * valores seguidos de las mismas letras indican que son estadísticamente iguales con $\mathrm{p}<0.05 \%$ 
en salmuera (mg de $\left.\mathrm{CO}_{2} 100 \mathrm{~mL}^{-1}\right)$, concentración de cloruro de sodio en salmuera (g $100 \mathrm{~mL}^{-1}$ ), concentración de azúcares reductores en fruto al mes

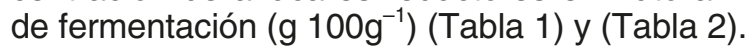

A la salmuera se le añadió inicialmente el $0.1 \%$ de ácido acético de calidad alimentaria, con objeto de corregir el $\mathrm{pH}$ inicial a valores menores a 4 . La aireación se realiza durante 8 horas diarias y el monitoreo de la salmuera se realizó semanalmente durante 90 días.

\subsection{Análisis Estadístico}

El análisis estadístico se realizó mediante el software Stat Graphic Centurión; utilizando la metodología de correlación entre las variables mediante el análisis de Pearson producto momento y la colección de los datos se realizó por 15 semanas, la correlación fue considerada con una significancia de $95 \%$ y se procesaron 1080 datos en to- tal. Se determinó el efecto de los factores en estudio, concentración de sal y caudal de aire mediante el análisis de Pareto con una significancia de 95\%; así mismo se realizó un análisis de varianza a los azúcares reductores en fruto después de un mes de fermentación.

\section{RESULTADOS Y DISCUSIÓN}

\subsection{Efecto del caudal de aire y concentración de sal en las características fisicoquímicas de la fermentación}

La acidez fija alcanzó valores finales de $1.2-1.5 \%$ (Figura 1) y la acidez libre valores entre de 1.5-2\%, Fernández (1991), reporta en fermentaciones aerobias de la variedad hojiblanca valores de acidez láctica que no superan el $0.4 \%$ debido al desarrollo únicamente de levaduras. Balatsouras (1966), menciona en el proceso de aceitunas negras natu-

Tabla 2

Determinación del efecto de los factores: caudal de aireación y concentración inicial de cloruro de sodio en la fermentación de aceituna negra natural, mediante el análisis de Pareto

\begin{tabular}{|c|c|c|c|c|}
\hline Variable Dependiente & Factor & Efecto & $\mathbf{R}^{2}$ ajustado & Valor $\mathbf{P}$ \\
\hline \multirow{3}{*}{$\begin{array}{l}\text { Levaduras anaerobias } \\
\text { facultativas }\end{array}$} & Aire & + & 84.22 & 0.0137 \\
\hline & Sal & + & & $0.0450^{\star}$ \\
\hline & Aire-Sal & - & & 0.3439 \\
\hline \multirow[t]{3}{*}{ Acidez fija } & Aire & + & 34.40 & 0.0734 \\
\hline & Sal & - & & 0.4265 \\
\hline & Aire-Sal & - & & 0.7200 \\
\hline \multirow[t]{3}{*}{ Dióxido de Carbono } & Aire & - & 97.97 & $0.0004^{\star}$ \\
\hline & Sal & + & & 0.7650 \\
\hline & Aire-Sal & + & & 0.5900 \\
\hline \multirow[t]{3}{*}{ Azúcares Reductores } & Aire & - & 72.13 & $0.0213^{\star}$ \\
\hline & Sal & + & & 0.5241 \\
\hline & Aire-Sal & - & & 0.4200 \\
\hline \multirow[t]{3}{*}{ Levaduras aerobias } & Aire & + & 64.98 & $0.0284^{\star}$ \\
\hline & Sal & - & & 0.7620 \\
\hline & Aire-Sal & + & & 0.6520 \\
\hline \multirow[t]{3}{*}{ Cloruros } & Aire & - & 97.85 & 0.2646 \\
\hline & Sal & + & & $0.0003^{\star}$ \\
\hline & Aire-Sal & - & & 0.3034 \\
\hline \multirow[t]{3}{*}{ Bacterias Lácticas } & Aire & + & 79.03 & $0.0389^{\star}$ \\
\hline & Sal & - & & 0.0372 \\
\hline & Aire-Sal & - & & 0.0810 \\
\hline
\end{tabular}

Nota: * efecto significativo con una probabilidad del $95 \%$

efecto (+) aumenta la concentración de la variable dependiente

efecto (-) disminuye la concentración de la variable dependiente 


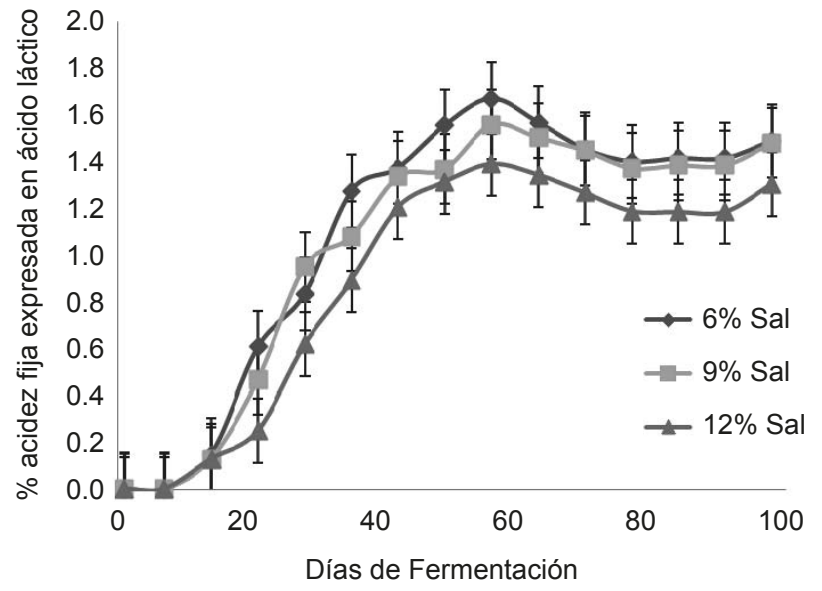

Figura 1

Evolución de acidez fija (expresada en \% de ácido láctico, p/v) según la concentración de sal inicial.

rales griegas una acidez entre $0.1 \%$ a $0.4 \%$, debido al uso elevado de sal en el proceso. En aceitunas negras naturales de la variedad de Taggiasca, la acidez libre no supera el $0.5 \%$ y la acidez fija no sobrepasa $0.3 \%$ (Amelio y De Mauro, 2000). Romeo et al. (2010), observaron en fermentaciones de las variedades Moresca y Giarrafa valores de acidez entre el $0.1 \%$ a $0.3 \%$, utilizando concentraciones de sal inicial de $8 \%$ y $15 \%$. En las experiencias con aceituna Sevillana, la concentración de acidez está significativamente afectada $(p<0.05)$ por la concentración inicial de sal (Tabla 2); disminuyendo la acidez a mayor concentración de cloruros. Además, hay que tener presente que las levaduras aerobias consumen el ácido láctico, y la acidez final es significativamente menor $(p<0.05)$ a mayor población de levaduras aerobias (Tabla 3). Sin embargo, en todos los tratamientos la acidez producida hace que descienda el $\mathrm{pH}$ hasta valores de 3.3-3.4 (Figura 2). En aceitunas negras naturales Jijelianas el pH osciló entre 5.4 y 5.8 . Idoui et al., (2009) y Balosturas (1966), reporta en aceitunas griegas un $\mathrm{pH}$ superior a 5.0 y en variedades italianas Moresca y Ogliarola el pH se mantuvo en valores superiores a 4.0 (Poiana, Romeo 2006), ello dificulta una adecuada conservación del fruto.

La alta concentración de ácido actúa sobre las antocianinas y convierte el color oscuro de la aceituna en un color violáceo (Durán et al., 1997), el cual es característico de la variedad Sevillana negra natural.

Las aceitunas negras con un índice de madurez de 4.5 (COI, 1985), presentaron una concentración inicial de azúcares reductores de $4.80 \%(p / p)$, esto contrasta con los valores de $1-2 \%$ encontrados en aceitunas de variedades españolas (Garrido et al., 1985), así como en las variedades italianas Nocellara etnea y San Agostino las cuales reportaron valores de 1.48 y $2.23 \%$, respectivamente (Garrido et al., 1985; Sciancalepore, 1984). La concentración de azúcares reductores en el fruto disminuyó a los 30 de días de fermentación a valores de 1.5\% ( $12 \%$ de sal), $0.9 \%$ ( $9 \%$ de sal) y $1.2 \%$ (6\% de sal) en los tratamientos sin aireación; sin embargo los

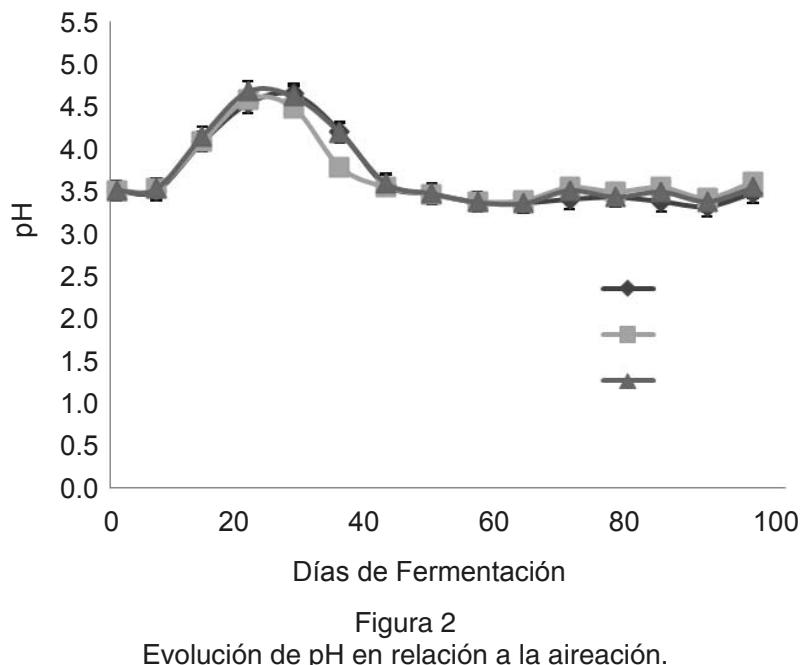

tratamientos con aireación de $0.1 \mathrm{~L} \mathrm{~h}^{-1}$, la concentración de azúcares fue de $0.53 \%$ (12\% de sal), $0.66 \%(9 \%$ de sal) y $0.53 \%(6 \%$ de sal) y los tratamientos con $0.2 \mathrm{~L} \mathrm{~h}^{-1}$ de aireación los resultados fueron de $0.53 \%$ ( $12 \%$ de sal), $0.37 \%$ ( $9 \%$ de sal) y 0.52 (6\% de sal) (Tabla 1). Fernández et al. (1992), indica que la presencia de valores finales del 0.4$0.5 \%$ de azúcares reductores en pulpa al final de la fermentación se debe a compuestos reductores con el licor Fehling o que estos azúcares se mantienen formando compuestos más complejos difícilmente hidrolizables. Según ello se puede afirmar que prácticamente se han consumido los azúcares en los tratamientos con aireación, mientras que en el proceso anaerobio queda todavía una cantidad considerable de ellos.

Sánchez et al. (2006), indican que el amargor del fruto desaparece más rápidamente en fermentaciones aerobias por a la rápida difusión de los azúcares y compuestos amargos en la salmuera, debido a la recirculación del líquido que lleva consigo la aireación, logrando que el producto esté apto para consumirse en sólo 3 meses.

En la salmuera la concentración de azúcares es muy baja debido a la lenta difusión de azúcares y a su consumo inmediato por los microorganismos (Fernández et al., 1992).

La sal tiende a equilibrarse osmóticamente entre el medio líquido y el fruto (jugo). Concentraciones altas de sal tienden a deshidratar el fruto y acumular cenizas en él, como lo han demostrado en variedades de Garriafa y Moresca de la zona de Sicilia (Romeo et al., 2010); la aireación disminuye la concentración de cloruros en salmuera pero no de manera significativa, esto se debe a la difusión entre el jugo celular y la salmuera. La sal se estabilizó en la salmuera, en un valor promedio de $4.23 \%$ para los tanques con concentración inicial del 6\%; 5.42\% con inicialmente $9 \%$ y $6.33 \%$ con el $12 \%$ (Figura 3 ).

El $\mathrm{CO}_{2}$ producido en la respiración de las aceitunas y en la actividad de los microorganismos se disuelve en la salmuera, en los tanques sin aplicación de aireación, el $\mathrm{CO}_{2}$ alcanzó concentraciones de $140 \mathrm{mg} 100 \mathrm{~mL}^{-1}$ (Figura 4), estos datos concuer- 
Tabla 3

Probabilidad de correlación entre los parámetros fisicoquímicos y microbiológicos en la fermentación aeróbica

\begin{tabular}{|c|c|c|c|c|c|c|c|}
\hline & $\begin{array}{c}\text { Acidez fija } \\
(\%)\end{array}$ & $\begin{array}{c}\text { Aireación } \\
L h^{-1}\end{array}$ & $\begin{array}{c}\text { Bacterias } \\
\text { Lácticas } \\
\text { Log ufc } \mathrm{mL}^{-1}\end{array}$ & $\begin{array}{c}\text { Cloruros } \\
\%\end{array}$ & $\begin{array}{c}\mathrm{CO}_{2} \\
\%\end{array}$ & $\begin{array}{l}\text { Levaduras } \\
\text { fermentativas } \\
\text { Log ufc } \mathrm{mL}^{-1}\end{array}$ & $\begin{array}{l}\text { Levaduras } \\
\text { aerobias } \\
\text { Log ufc } \mathrm{mL}^{-1}\end{array}$ \\
\hline Aireación $\mathrm{L} \mathrm{h}^{-1}$ & 0,5434 & & & & & & \\
\hline $\begin{array}{l}\text { Bacterias } \\
\text { Lácticas } \\
\text { Log ufc } \mathrm{mL}^{-1}\end{array}$ & 0,6310 & 0,8954 & & & & & \\
\hline Cloruros\% & $0,0000^{*}$ & 0,2642 & $0,0002^{*}$ & & & & \\
\hline $\mathrm{CO}_{2} \%$ & $0,0002^{*}$ & $0,0000^{*}$ & 0,632 & 0,0105 & & & \\
\hline $\begin{array}{l}\text { Levaduras } \\
\text { fermentativas } \\
\text { Log ufc } \mathrm{mL}^{-1}\end{array}$ & $0,0446^{\star}$ & 0,3952 & $0,0297^{*}$ & 0,3984 & 0,3647 & & \\
\hline $\begin{array}{l}\text { Levaduras } \\
\text { aerobias } \\
\text { Log ufc } \mathrm{mL}^{-1}\end{array}$ & $0,0354^{*}$ & $0,0065^{*}$ & 0,9334 & 0,0780 & $0,0001^{*}$ & 0,5421 & \\
\hline
\end{tabular}

Nota: * efecto significativo con una probabilidad del $95 \%$

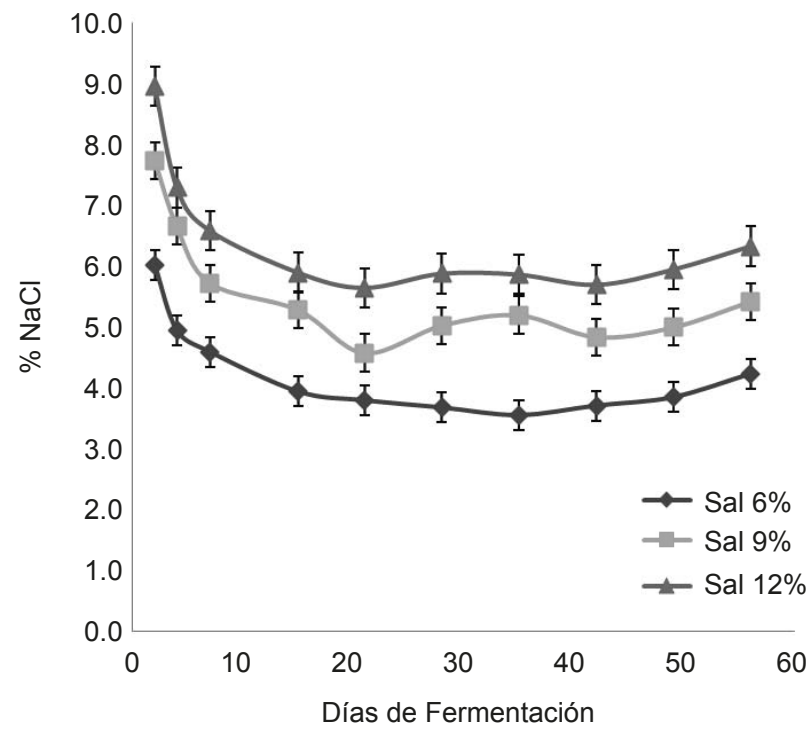

Figura 3

Evolución de la concentración de $\mathrm{NaCl}$ en salmuera en relación a la sal inicial.

dan con los obtenidos por Fernández et al. (1992), reportando niveles de 150 a $200 \mathrm{mg} 100 \mathrm{~mL}^{-1}$ en fermentadores industriales de $16000 \mathrm{~L}$.

Durante el primer mes de fermentación en los tanques aireados con caudales de $0.2 \mathrm{~L} / \mathrm{h} / \mathrm{Lc}$ y $0.1 \mathrm{~L} / \mathrm{h} / \mathrm{Lc}$, los valores de $\mathrm{CO}_{2}$ disuelto en salmuera se mantuvieron en $80-50 \mathrm{mg} / 100 \mathrm{ml}$; posteriormente descendió hasta niveles de $15-30 \mathrm{mg} 100 \mathrm{~mL}^{-1}$ (Figura 4), posteriormente el $\mathrm{CO}_{2}$ es eliminado casi completamente, siendo lógicamente el efecto de la aireación estadísticamente significativo (Tabla 2). En fermentaciones de aceitunas var. Hojiblanca con aireación de $0.3 \mathrm{~L} / \mathrm{h} / \mathrm{Lc}$, la acumulación de $\mathrm{CO}_{2}$ alcanzó valores de $40-60 \mathrm{mg} 100 \mathrm{~mL}^{-1}$ de salmuera, y luego de los 60 días el $\mathrm{CO}_{2}$ disminuyó a valores menores a $10 \mathrm{mg} 100 \mathrm{~mL}^{-1}$, esto se debe a que

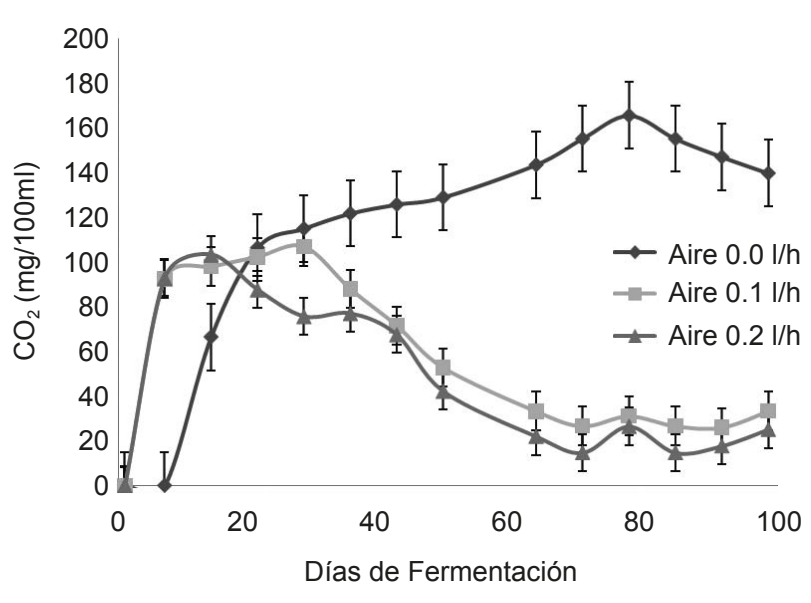

Figura 4

Evolución del $\mathrm{CO}_{2}$ en salmuera en relación a la aireación.

el caudal de aire no es suficiente para eliminar el $\mathrm{CO}_{2}$ proveniente del propio metabolismo del fruto y la actividad microbiana (Fernádez et al., 1992). Asimismo, la concentración de $\mathrm{CO}_{2}$ se relacionó directamente con la concentración de cloruros en salmuera (Tabla 2).

\subsection{Efecto del aire y concentración de sal en la evolución de la flora microbiológica en la fermentación}

Los gram negativos o Enterobacteriaceas se detectan a los 2 días de iniciada la fermentación debido a que el $\mathrm{pH}$ inicial fue modificado por la adición de ácido acético, luego el pH se incrementa a valores superiores a 4.5 lo que permite el desarrollo de las enterobacterias, en las experiencias el pH llega a alcanzar valores cercanos a 5 debido a la difusión del jugo celular del fruto en el líquido (Figura 2). La población máxima de gram negativos fue de $1.8 \times 10^{3}$ ufc $\mathrm{mL}^{-1}$ en los tanques con $0.2 \mathrm{~L} \mathrm{~h}^{-1}$ 
de aireación (Figura 5). Se observó una mayor población de las Enterobacteriaceas cuando se airea la salmuera. Estos microorganismos deben desaparecer al momento en el que se alcanza un $\mathrm{pH}$ de 4.2 que es el límite que permite su desarrollo (Peres et al., 2008). La aireación, en fermentaciones naturales de aceitunas negras Jijileanas reporta una población entre 1.01 a $5 \times 10^{5}$ ufc $\mathrm{mL}^{-1}$ de gram negativos (Idoui et al., 2009). Esto indica un menor desarrollo de los gram negativos en nuestro caso, debido a las buenas prácticas de manufactura como lavado, desinfección de los tanques y cloración del agua de fermentación, así mismo la adición de ácido acético al $0.1 \%$ que disminuye el desarrollo de estos microorganismos durante la primera semana.

Los mohos solamente se detectaron durante los primeros dos días, posteriormente las levaduras predominan en la fermentación y las levaduras anaerobias facultativas o fermentativas se desarrollaron mejor en los tratamientos con concentraciones mayores de sal, determinando un efecto significativo de esta variable (Tabla 2) predominando las especie Saccharomyces cereviseae, además, se aislaron las especies de Candida lipolytyca y Cryptococcus laurenti en menor concentración (datos no mostrados); las levaduras aerobias del género Geotrichum klebani, Candida culliculosa, Candida boidini, Candida lipolytyca y Cryptococcus humicola se desarrollan mejor en los tratamientos con la aireación (Tabla 2). Sin embargo no sobrepasaron poblaciones de $10^{5}$ ufc $\mathrm{mL}^{-1}$ (Figura 6). La población de levaduras correlaciona con la acidez láctica (Tabla 3), debido a que estos microorganismos consumen el ácido láctico y producen ácido acético, como indican Ruiz-Mollano et al. (2009). Las levaduras anaerobias facultativas son principalmente del género Saccharomyces cereviceae, y se detectan en mayor concentración al inicio de la fermentación lo que concuerda con los resultados obtenidos por Kanavouras et al. (2005) y Durán et al. (2003); estas especies producen el $\mathrm{CO}_{2}$ que se acumula al inicio de la fermentación y desarrollaron mejor con concentraciones iniciales del $12 \%$ de sal (Figura 7 ); sin embargo la aireación elimina el $\mathrm{CO}_{2}$ acumulado

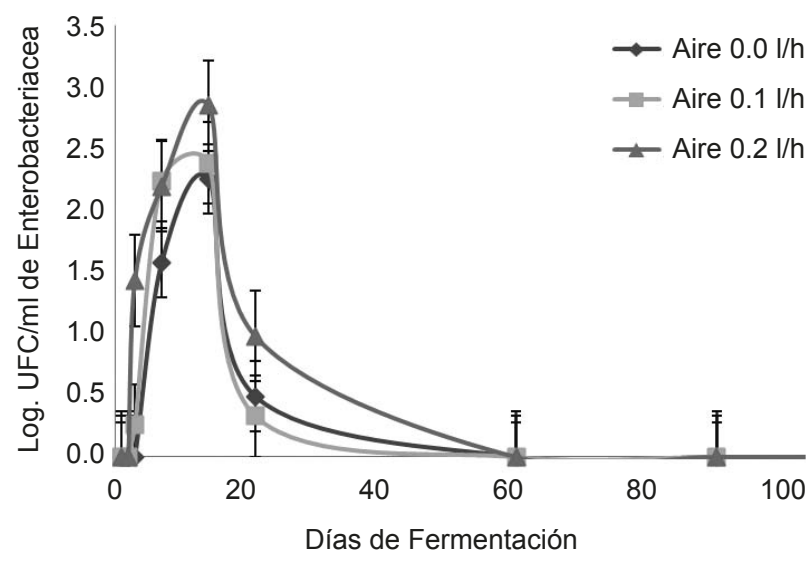

Figura 5

Evolución de Enterobacteriaceas en relación a la aireación.

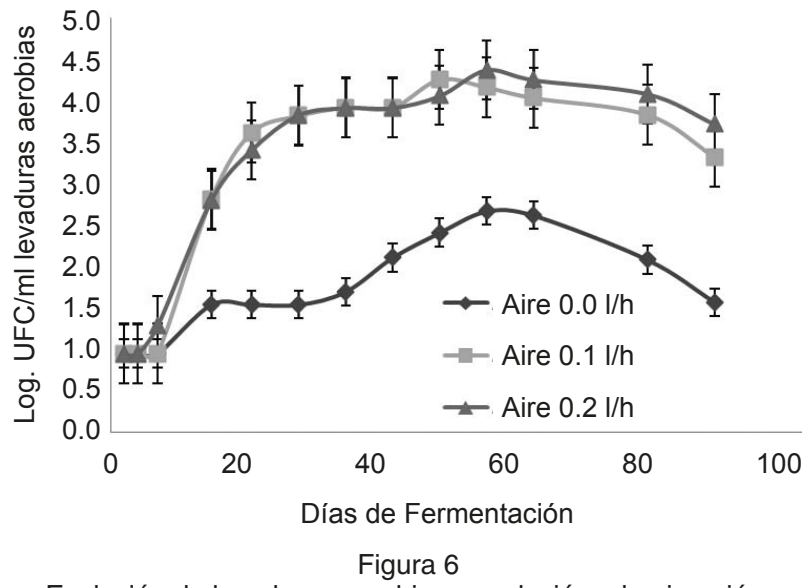

Evolución de levaduras aerobias en relación a la aireación.

por estos microorganismos, (Garrido et al., 1985). Investigaciones desarrolladas por Benites y Carrillo (2004), demostraron la acción antagónicas de Candida boidini contra cepas de Penicillum spp, de igual manera fue demostrado por Ruiz-Mollano et al. (2009), la acción de Candida boidini y Candida colliculosa contra Penicillum expansum, Aspergillus flavus y Penicillium glabarum, estos hongos tienen actividad pectinolítica ablandando y manchando la aceituna durante la fermentación.

Los recuentos de levaduras fermentativas en los tratamientos con sal inicial del $12 \%$ reportaron valores superiores a $10^{5}$ ufc $\mathrm{mL}^{-1}$, sin embargo en los tanques fermentados con el $6 \%$ de sal el desarrollo de las levaduras fermentativas no sobrepasó los valores de $10^{4}$ ufc $\mathrm{mL}^{-1}$ (Figura 7); el desarrollo de levaduras es menor con respecto a fermentaciones negras naturales de Jijilea, en las cuales se reportan valores superiores a $10^{6}$ ufc $\mathrm{mL}^{-1}$ (Idoui et al., 2009). Así mismo en variedades Sicilianas Moresca y Ogliarola la concentración de levaduras supera $10^{5}$ ufc $\mathrm{mL}^{-1}$ tal como lo reportan Poiana y Romeo (2006). La acumulación del $\mathrm{CO}_{2}$ no tiene una correlación con el desarrollo de las levaduras anaerobias facultativas (Tabla 3 ), debido a que al inicio de la fermentación el $\mathrm{CO}_{2}$ que se elimina es producto de la respiración del fruto; García et al.

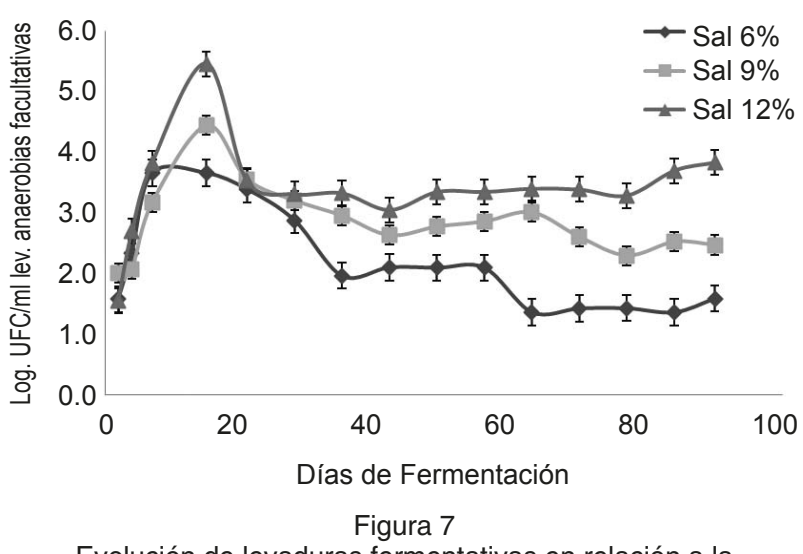

Evolución de levaduras fermentativas en relación a la concentración de sal inicial. 
(1995) estudiaron la respiración de aceitunas de las variedades Gordal y Manzanilla encontrando que llegan a producir 60 y $40 \mathrm{~mL}$ de $\mathrm{CO}_{2} \mathrm{~kg}^{-1}$ de fruto respectivamente durante el primer día de la recolección a $20^{\circ} \mathrm{C}$.

La presencia de levaduras en la fermentación de aceitunas negras es fuente de controversia, debido al exceso de producción de $\mathrm{CO}_{2}$ el cual causa alambrado en el fruto, siendo las principales especies Saccharomyces cereviceae y Pichia anomala tal como indican Durán et al. (2005), así mismo en aceitunas españolas las levaduras son los microorganismos que producen las características organolépticas de las aceitunas negras naturales, sin embargo en las aceitunas de la variedad Sevillana también predomina el sabor láctico. El sistema de aireación permite disminuir el $\mathrm{CO}_{2}$ producido por microorganismos heterofermentativos y la aplicación de aireación a 0.1 y $0.2 \mathrm{~L} / \mathrm{h} / \mathrm{Lc}$ no ha incrementado considerablemente el desarrollo de levaduras, no sobrepasando valores mayores a $10^{5}$ ufc $\mathrm{mL}^{-1}$.

Las bacterias ácido lácticas se han desarrollado normalmente en todos los tratamientos, este tipo de bacterias han sido favorecidas por la aireación al $0.1 \mathrm{~L} / \mathrm{h} / \mathrm{Lc}$ (Figura 8), por lo tanto la aireación tienen efecto positivo en el desarrollo de bacterias lácticas (Tabla 1). Las especies que predominan en la primera semana de fermentación en los tanques con aireación, fueron Pediococcus sp y Leuconostoc sp, incrementando su población a valores mayores a $10^{7}$ (datos no mostrados), en la fermentación anaerobia se empezaron a desarrollar a la segunda semana. En los tratamientos sin aireación con sal al $12 \%$, el desarrollo de lactobacilos fue más lento, así mismo en los tanques con aireación y concentraciones de sal de $6 \%$, los lactobacilos se desarrollaron más rápidamente y alcanzaron poblaciones mayores a $10^{8}$ ufc $\mathrm{mL}^{-1}$ (Figura 8), debido a que en todos los tratamientos la concentración de cloruros se mantuvo por debajo de $6 \%$. Se observó una fuerte correlación entre la concentración de cloruros en salmuera, la evolución de lactobacilos y la producción de acidez (Tabla 3), ello también se pone de manifiesto en otras variedades de aceituna como

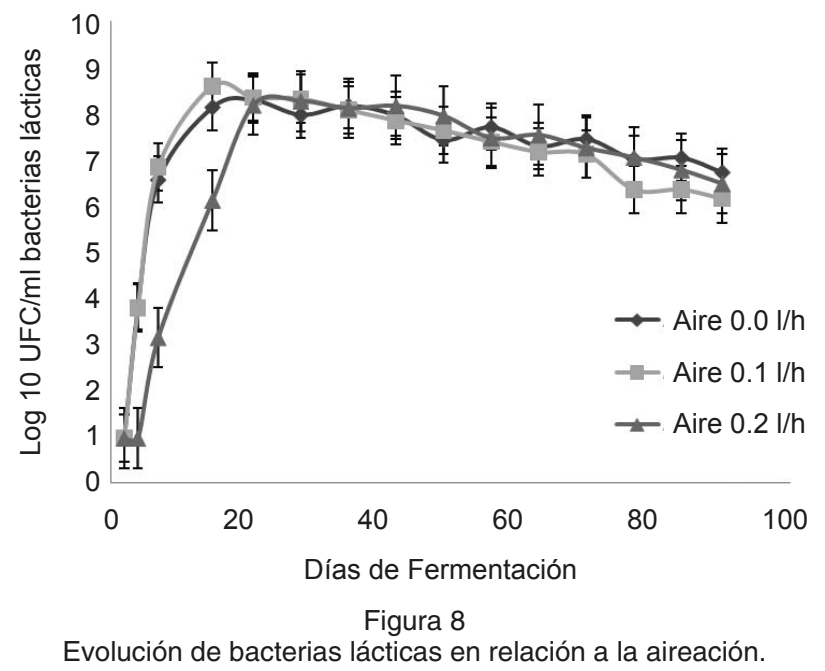

Nocellara del Belice preparadas al natural (Romero et al., 2012). El incremento de acidez ayuda a inhibir el amargo, debido a la degradación de la oleuropeína a otros compuestos fenólicos no amargos principalmente a hidroxitirosol (Ciafardini et al., 1994; Landete et al., 2007; Rodriguez et al., 2009). También actúa la enzima beta-glucosidasa producida por los microorganismos para degradar la oleuropeína, como lo observaron Ghabbour et al., (2011), estas investigaciones también determinaron a los microorganismos que intervienen en este proceso y detectaron principalmente la presencia de Lactobacillus pentosus y Lactobacillus plantarum; en la fermentación de aceituna sevillana predomina Lactobacilos pentosus el cual fue identificado utilizando el sistema API $50 \mathrm{CH}$ Biomerux.

El cloruro de sodio se estabilizó en concentraciones menores a $6.5 \%$ en todos los tratamientos y esto favoreció el desarrollo de Lactobacillus pentosus. Los polifenoles como la oleuropeína tienen un carácter antioxidante (Arslan y Özcan, 2011) e inhibidor in vitro de las bacterias lácticas, esto fue determinado por (Ruiz Barba, 1991; Ruiz Barba et al., 1990 y 1991), sin embargo trabajos realizados por Rozes y Peres (1996), han encontrado que la oleuropeína por sí sola no tiene un efecto inhibidor contra lactoctobacilos, en cambio cuando se forma la aglucona, por acción de la beta-glucosidasa si disminuye el recuento de lactobacilos, esto concuerda con los elevados recuentos al inicio de la fermentación donde los polifenoles se encuentran en altas concentraciones, sin embargo el desarrollo de otros microorganismos como las enterobacterias se ve inhibida desde las primeras semanas. Esto nos indica que el desarrollo de los lactobacilos en la aceituna negra natural variedad Sevillana, no se inhiben por la presencia de oleuropeína y que las bacterias lácticas tienen la capacidad de hidrolizar este compuesto.

\section{CONCLUSIONES}

El efecto de la aireación en la fermentación de aceituna negra natural sevillana, purga el $\mathrm{CO}_{2}$ producido teniéndose concentraciones menores de $30 \mathrm{mg} \mathrm{mL}^{-1}$ y favorece el crecimiento de una microflora de metabolismo aerobio. Disminuyendo la concentración de sal se favorece el crecimiento de bacterias lácticas y no hay un efecto negativo con la aplicación de aire, la principal especie que predomina en la fermentación es Lactobacillus pentosus. La fermentación con concentraciones iniciales de sal de 6-9\% permite una fermentación láctica alcanzando valores de acidez fija de $1.5 \%$, sin embargo a concentraciones de $12 \%$ el desarrollo de levaduras fermentativas participan al inicio de la fermentación alcanzando una acidez menor del $1.2 \%$.

\section{AGRADECIMIENTOS}

Al FINCyT-PITEI 2010. A la empresa Biondi y Cía. de Tacna S.A.C., al Laboratorio CITELAB del 
Módulo de Servicios Tacna CITE Agroindustrial, Al Instituto de la Grasa en especial a los Doctores: Manuel Brenes, Pedro García y Antonio de Castro por sus aportes y consejos en el desarrollo de este trabajo.

\section{REFERENCIAS}

Amelio M, De Mauro E. 2000. Naturally fermented black olives of Taggiasca variety (Olea europea L.). Grasas Aceites 51, 429-439.

AOAC 2007. Official Methodos of Analysis, 18th Ed., AOAC International

Arslan, D. Özcan, M.M. 2011. Phenolic prolife and antioxidant activity of olive fruits of the Turkish variety "Sariuak" from different locations. Grasas Aceites 62, 453-461.

Balatsouras D. 1966. The chemical composition of the brine of stored Greek black olives. Grasas Aceites 17, 83-88.

Benites M, Carrillo L. 2004. Levaduras inhibidoras de Penicillium. Revista Argentina de Microbiología 36, 182186.

Ciafardini G, Marsillo V, Lanza B, Pozzi N. 1994. Hydrolysis of oleuropein by Lactobacillus plantarum strains associated with olive fermentation. Appl Environ. Microbiol. 60, 4142-4147.

CONSEJO OLEICO INTERNACIONAL, C.O.I. 1985. «Las aceitunas de mesa», OLIVAE (España) 2, 18-25.

Durán C, García P, Garrido A. 2003. Características del crecimiento de levaduras de aceitunas de mesa a bajas temperaturas. Grasas Aceites 54, 264-271.

Durán C, González F, Garrido A. 1979. Aceitunas negras al natural en salmuera IX. Ensayos de producción del 'alambrado' por incubación de diversos microorganismos aislados de salmuera de fermentación. Grasas Aceites 30, 361-367.

Durán C, Noé F, García P, Garrido A. 2005. Evolución del crecimiento en salmuera, a bajas temperaturas y diferentes acidulantes, de levaduras aisladas de aceitunas de mesa. Grasas Aceites 56, 9-15.

Durán C, Romero O, García P, Brenes M, Garrido A. 1997. Bacterias del ácido láctico en la fermentación de aceitunas de mesa. Grasas Aceites 48, 297-311.

Fernández J, Castro R, Garrido A, Heredia A, Nosti M, Castro A. 1985. «Biotecnología de la aceituna de mesa». Consejo Superior de Investigaciones Científicas. Madrid-Sevilla.

Fernández J, Garrido A, García P, Brenes M, Duran C. 1992. Características del proceso fermentativo durante la conservación de aceitunas de la variedad Hojiblanca, destinadas a la elaboración del tipo negras. Grasas Aceites 43, 212-218.

Fernández M. 1991. Frutos y vegetales aderezados. Grasas Aceites 42, 74-83.

García P, Brenes M, Romero C, Garrido A. 1995. Respiration and physicochemical changes in harvested olive fruits. J. Hort. Sci. 70, 925-933.

García P, Durán C, Garrido A. 1985. Fermentación aerobia de aceitunas maduras en salmuera. Grasas Aceites 36, 14-20.

Garrido A, Fernández M, Adams M. 1997. "Table olive”. Chapman \& Hall Eds., Publisher London, UK.

Garrido A, García P, Durán C. 1985. Conservación de aceitunas negras naturales procedentes de fermentación anaeróbica. Grasas Aceites 36, 313-316.
Ghabbour N, Lamzira Z, Thonart P, Cidalia P, Markaoui M, Asehraou A. 2011. Selection of oleuropein- degrading lactic acid bacteria strains isolated from fermenting Moroccan green olives. Grasas Aceites 62, 84-89.

ICMSF 1983. "International Commision on Microbiological Specifications for Foods". Microorganismos de los alimentos. Vol. 1. Técnicas de Análisis Microbiológicos. Editorial Acribia. Zaragoza, España.

Idoui T, Boudjerda J, Leghouchi E, Karam N. 2009. Naturally fermented Jijelian black olives: microbiological characteristics and isolation of lactic acid bacteria. Grasas Aceites 60, 514-518.

Kanavouras A, Gazouli M, Tzouvelekis L. 2005. Evaluation of blacks tables olives in different brines. Grasas Aceites 56, 106-115.

Landete M, Curiel A, Rodriguez $\mathrm{H}$, de Las Rivas B, Munoz R. 2007. High-added-value antioxidants obtained from the degradation of wine phenolics by Lactobacillus plantarum. J. Food Protect. 70, 2670-2675.

Nelson J. 1944. A photometric adaptation of the Smogyi methods for the determination of the glucose. J. Biol. Chem. 153, 375-380.

Peres C, Catulo L, Brito D, Pintado C. 2008. Lactobacillus pentosus DSM 16366 starter added to brine as freeze-dried and as culture in the nutritivee media for spanish style green olive production. Grasas Aceites 59, 234-238.

Poiana M, Romeo F. 2006. Changes in chemical and microbiological parameters of some varieties of Sicily olives during natural fermentation. Grasas Aceites 57, 402-408.

Ramos I, Bucio A, Bautista C, Aranda E, Izquierdo F. 2009. Aislamiento, Identificación y Caracterización de bacterias ácido lácticas para la elaboración de queso crema tropical. Tabasco, México. Universidad y Ciencia. 25, 159-171.

Rodríguez $\mathrm{H}$, Curiel A, Landete $\mathrm{M}$, de las Rivas $\mathrm{B}$, de Felipe P, Cordoves G, Mancheno M, Munoz R. 2009. Food fenolic and lactic bacteria. Int J. Food Microbiol. 132, 79-90.

Romeo F, Piscopo A, Poiana M. 2010. Effect of acidification and salt concentration on two black brined olives from Sicily (cv moresca and giarraffa). Grasas Aceites 61, 251-260.

Romero, F.V., Piscopo, A., Mincione, A. Poiana, M. 2012. Quality evaluation of different typical table olive preparations (cv Noceralla del Belice). Grasas Aceites 63 19-25.

Rozes N, Peres C. 1996. Effect of oleuropein and sodium chloride on viability and metabolism of Lactobacillus plantarum. Appl. Microbiol. Biotechnol. 45, 839-843.

Ruiz L, Rios M, Fedraiani C, Olias M, Rios L, Jimenez R. 1990. Bactericidal effect of phenolic compounds from green olives on Lactobacillus plantarum. Syst. Appl. Microbiol. 13, 199-205.

Ruiz-Moyano S, González A, Hernández A, Casquete R. 2009. Nuevas Tecnologías en la elaboración de la aceituna de mesa. La agricultura y la ganadería Extremeña 105-119.

Sánchez H, García P, Rejano L. 2006. Elaboration of table olives. Grasas Aceites 57, 86-94.

Sciancalepore V. 1984. La temperature di deamerizatione nella preparazzione delle olive verdi col sistema Sivigliano. Industrie Alimentari 23, 941-944.

Recibido: 23/11/12 Aceptado: 6/2/13 